\title{
Scleral contact lens wear in unilateral aphakia
}

\author{
P. V. MILLS AND E. M. TERRY LEWIS
}

Department of Ophthalmology, Cardiff Royal Infirmary

It has been shown that the wearing of contact lenses prescribed for the optical correction of unilateral aphakia is not well maintained in patients fitted with either scleral lenses (Ruben, I962; Bonnet, Gerhard, and Massin, I966) or microcorneal lenses (Bonnet and others, 1966). Some of the causes for this failure of contact lens wear were analysed by Gerhard and Bronner ( 1965 ), who found that the failure rate was independent of the type of contact lens fitted.

In the patients who are unable to tolerate the contact lens because of irritation or who experience difficulty in its handling, it would be reasonable to expect that a more satisfactory long-term binocular visual result would be obtained by the use of an intraocular acrylic lens implant. Such an implant would have no advantage in patients intolerant of the lens because of heterotropia and, although the difference in retinal image size between the phakic and the correlated aphakic eye is reduced from an average of 6.99 per cent. with a contact lens to I.92 per cent. with an intraocular lens (Girard, Friedman? Moore, Blau, Binkhorst, and Gobin, I962), good binocular vision is usually achieved by either method. Girard and others (1962), including his co-author C. D. Binkhorst therefore concluded that a contact lens should be tried first in all cases in preferencê to an intraocular lens, and this approach is now widely accepted.

However, Binkhorst and Leonard ( 1967 ), in reporting the results of 208 implantations of the iris-clip pseudophakos (Binkhorst, I959), concluded that primary implantation of this device at the time of the cataract extraction is preferable to its secondary implantation, as surgical corneal dystrophy occurred in five eyes $(7 \cdot I$ per cent.) with secondary implantation and none with primary implantation. In a subsequent paper (Binkhorst, Gobin, and Leonard, 1969), it was stated that a contact lens should not be used to correct post-traumatic aphakia in children, because the authors considered that this reduced the chance of binocular re-education (Binkhorst and Gobin, 1967).

The justification for primary implantation of an intraocular lens to correct unilateral aphakia would be greater if it were possible to predict before the cataract extraction that successful contact lens wear was improbable. The present study, undertaken in an attempt to define factors which might militate against the successful wearing of a contact lens in unilateral aphakia, consists of the analysis of data relating to such patients fitted with a contact lens by one of us (E.M.T.L.) at the Cardiff Royal Infirmary between I96I, when the service was commenced, and the end of 1966 .

\section{Material and Methods}

A circular and questionnaire were sent to the last known address of each patient with unilateral aphakia who was fitted with contact lenses at the Cardiff Royal Infirmary between I96i and I966 inclusive. Patients who failed to reply to the first circular were sent a further copy and those who 
still failed to reply were traced wherever possible by the staff of the Medical Research Council, Epidemiological Research Unit (South Wales). The patients' hospital records and contact lens notes were then examined to obtain other relevant information and this was collated with the replies to the questionnaire.

All patients who had their follow-up at the Cardiff Royal Infirmary subsequent to contact lens fitting were included in the study, even if the cataract operation had been performed elsewhere. Patients who attended the Cardiff Royal Infirmary for contact lens fitting only, having had both the cataract operation and subsequent follow-up elsewhere, were excluded from the study.

The patients were selected for contact lens fitting according to the criteria of the individual consultant surgeon but, with the exception of two cases, it is evident that the criteria included a visual acuity of at least $6 / 18$ in the aphakic eye with the contact lens.

Patients were fitted with scleral lenses as a normal procedure in preference to micro-corneal lenses because of the ease of handling the large lens, the minimum risk of loss or damage and possible extra expense both to the patient and the National Health Service, and the great ease of fitting and supplying these lenses.

The scleral lenses fitted were all fenestrated minimum clearance impression lenses with doublecurve optic and deep channel transition (Lewis, 1970). A micro-corneal lens was fitted initially in seven patients, five of whom were subsequently re-fitted with a scleral lens. The remaining two patients in this group were excluded from the study.

The patients were refracted with a contact lens in situ and impressions were made during the first appointment. The completed contact lens was usually supplied on the second visit and the followup continued over 5 months to ensure that the lens settled properly on the eye and that the patient was wearing it without difficulty. This required at least five report appointments, after approximately $2,6,10,15$, and 20 weeks.

Patients were requested to report back between appointments should difficulty be experienced and to make a new appointment should any problem arise subsequent to their discharge from the contact lens clinic. Many of the patients continued to attend the surgeon's clinics after discharge from the contact lens clinic.

\section{Results}

I 56 patients were reviewed ( 104 males and 52 females). The age distribution is shown in Table I and the period in years between the supply of the contact lens and the date of review in Table II. Within this group ten patients had died before the review, twelve could not be traced, and two had lost all useful vision in the aphakic eye, through secondary glaucoma and retinal detachment respectively.

Table I Age and sex incidence in 156 cases

\begin{tabular}{|c|c|c|c|}
\hline Age (yrs) & Male & Female & Total \\
\hline $0-9$ & I & 0 & I \\
\hline I O-I 9 & 8 & o & 8 \\
\hline $20-29$ & IO & I & I I \\
\hline $30-39$ & 7 & 4 & I I \\
\hline $4^{0-49}$ & 22 & 4 & 26 \\
\hline $5^{0}-59$ & 2 I & 20 & $4^{I}$ \\
\hline $6 o-69$ & 26 & I 5 & 41 \\
\hline $70-79$ & 8 & 8 & I 6 \\
\hline $80-89$ & I & o & $\mathbf{I}$ \\
\hline Total & 104 & $5^{2}$ & 56 \\
\hline
\end{tabular}

Table II Duration of follow-up in I 56 cases

\begin{tabular}{|c|c|c|}
\hline $\begin{array}{l}\text { Follow-up } \\
(y r s)\end{array}$ & $\begin{array}{l}\text { Number of } \\
\text { patients }\end{array}$ & $\begin{array}{l}\text { Year when contact } \\
\text { lens was fitted }\end{array}$ \\
\hline 7 & 4 & I 96 I \\
\hline 6 & 28 & I 962 \\
\hline 5 & 28 & I 963 \\
\hline 4 & 30 & I 964 \\
\hline 3 & 33 & I 965 \\
\hline 2 & 33 & I 966 \\
\hline
\end{tabular}


The remaining $13^{2}$ patients reported that their use of the contact lens at the review date was as shown in Table III. This series includes $3^{2}$ patients who had had a subsequent cataract extraction on the second eye, in eleven of whom the contact lens was no longer worn, but it should be noted that only two of the latter failed to wear the contact lensō during the period of monocular aphakia.

Table III Contact lens wear in 132 patients

\begin{tabular}{|c|c|c|}
\hline Contact lens wear at review date & $\begin{array}{l}\text { Number of } \\
\text { patients }\end{array}$ & $\begin{array}{l}\text { Per cent. of } \\
\text { total patients }\end{array}$ \\
\hline $\begin{array}{l}6 \text { or more hrs daily } \\
\text { Less than } 6 \text { hrs daily } \\
\text { Worn after refit elsewhere }\end{array}$ & $\left.\begin{array}{r}53 \\
15 \\
3\end{array}\right\}$ & 54 \\
\hline No longer worn & $6 I$ & 46 \\
\hline Total & 132 & 100 \\
\hline
\end{tabular}

In all patients who had a cataract extraction on the second eye, the aetiology of the cataract was non-traumatic. These patients were excluded from further analysis, as they $\rightarrow$ were no longer uniocular aphakics by the time of the review. The three patients success- $\mathbb{T}$ fully re-fitted with micro-corneal contact lenses elsewhere, having been unable to tolerate the haptic contact lens fitted initially, were also excluded since no detailed information was available relevant to these lenses. One further patient whose hospital records were $\vec{\varphi}$ unobtainable was also excluded.

There thus remained 96 patients fitted with a scleral contact lens for unilateral aphak who retained useful vision in the operated eye at the review date. Table IV relate contact lens wear in this group to the aetiology of the cataract which required extraction irrespective of the duration of follow-up. The non-traumatic group includes cataract associated with chronic iridocyclitis, heterochromic cyclitis, diabetes mellitus, dystrophia $\stackrel{\mathbb{D}}{\Omega}$ myotonica and atopic eczema, senile cataract, unilateral congenital cataract, cataract following glaucoma surgery, and cataract following radiotherapy for a rodent ulcer.

Table IV Contact lens wear related to aetiology in 96 patients available at the review date

\begin{tabular}{|c|c|c|c|}
\hline \multirow{2}{*}{ Aetiology of cataract } & \multicolumn{2}{|c|}{ Contact lens } & \multirow{2}{*}{$\begin{array}{l}\text { Total } \\
\text { cases }\end{array}$} \\
\hline & Worn & Not worn & \\
\hline $\begin{array}{r}\text { Traumatic Penetrating } \\
\text { Non-penetrating }\end{array}$ & $\begin{array}{l}6 \\
6\end{array}$ & $\begin{array}{l}\text { I3 } \\
\text { I0 }\end{array}$ & $\left.\begin{array}{l}19 \\
16\end{array}\right\} 35$ \\
\hline Non-traumatic & 35 & 26 & $6 r$ \\
\hline Total & 47 & 49 & $9^{6}$ \\
\hline
\end{tabular}

Though the numbers involved are necessarily small, patients who had sustained nonpenetrating injuries did not wear their lenses substantially better than those who had $\stackrel{\mathscr{D}}{?}$ penetrating injuries and therefore the traumatic group is considered as a single entity in 
subsequent Tables. It is also evident that those in the non-traumatic group wore their lenses considerably better than those in the traumatic sub-groups.

Table $\mathrm{V}$ indicates that this difference may be partly due to disparity in the duration of follow-up between the traumatic and non-traumatic cases. However, the same Table suggests that, in respect of the non-traumatic group, there is no appreciable reduction in the proportion of contact lenses worn after 2 years from the time of fitting, this being the minimum follow-up period in the sample studied. This is in direct contrast to the smaller traumatic group in which the proportion of contact lenses worn decreases the longer the follow-up period.

Table $\mathbf{V}$ Contact lens wear related to duration of follow-up in 96 patients

\begin{tabular}{|c|c|c|c|c|c|c|}
\hline \multirow{3}{*}{$\begin{array}{l}\text { Follow-up } \\
(y r s)\end{array}$} & \multicolumn{6}{|c|}{ Contact lens } \\
\hline & \multicolumn{3}{|l|}{ Worn } & \multicolumn{3}{|l|}{ Not worn } \\
\hline & Traumatic & Non-traumatic & Total & Traumatic & Non-traumatic & Total \\
\hline 7 & o & I & I & o & I & I \\
\hline 6 & 2 & 4 & 6 & I I & 6 & I 7 \\
\hline 5 & 4 & 4 & 8 & 6 & 0 & 6 \\
\hline 4 & 0 & 8 & 8 & 2 & 7 & 9 \\
\hline 3 & 3 & 9 & 12 & 4 & 5 & 9 \\
\hline 2 & 3 & 9 & 12 & o & 7 & 7 \\
\hline Total & 12 & 35 & 47 & 23 & 26 & 49 \\
\hline
\end{tabular}

Table VI relates contact lens wear to the age of the patient when the lens was supplied. Failure to maintain contact lens wear occurred in the majority of patients under the age of 50 years, irrespective of the aetiology of the cataract. Since younger patients are more numerous in the traumatic group, this age factor may also be relevant to the poor results obtained following trauma.

Table VI Contact lens wear related to age in 96 patients

\begin{tabular}{|c|c|c|c|c|c|c|}
\hline \multirow{3}{*}{$\begin{array}{l}\text { Age } \\
(y r s)\end{array}$} & \multicolumn{6}{|l|}{ Contact lens } \\
\hline & \multicolumn{3}{|l|}{ Worn } & \multicolumn{3}{|l|}{ Not worn } \\
\hline & Traumatic & Non-traumatic & Total & Traumatic & Non-traumatic & Total \\
\hline o-9 & o & o & o & o & o & o \\
\hline $10-19$ & o & I & I & 6 & o & 6 \\
\hline $20-29$ & I & o & I & 7 & 2 & 9 \\
\hline $30-39$ & 3 & I & 4 & I & 3 & 4 \\
\hline $40-49$ & 2 & 6 & 8 & 4 & 7 & I I \\
\hline $5^{0-59}$ & 2 & 14 & I6 & 4 & 4 & 8 \\
\hline $6 o-69$ & 3 & Io & I3 & I & 6 & 7 \\
\hline $70-79$ & I & 3 & 4 & o & 4 & 4 \\
\hline Total & & & 47 & & & 49 \\
\hline
\end{tabular}

Table VII (overleaf) relates contact lens wear to the sex of the patient. The slightly poorer overall results obtained in men are due to the much greater frequency of traumatic 


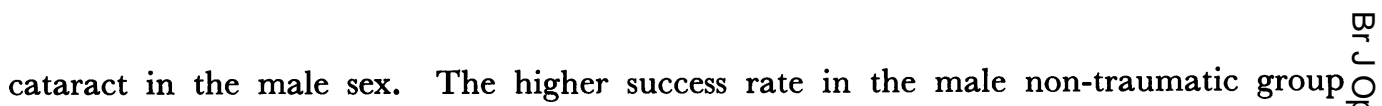
compared with the female should be noted.

Table VII Contact lens wear related to sex in 96 patients

\begin{tabular}{|c|c|c|c|c|c|c|}
\hline \multirow{3}{*}{ Sex } & \multicolumn{6}{|l|}{ Contact lens } \\
\hline & \multicolumn{3}{|l|}{ Worn } & \multicolumn{3}{|l|}{ Not worn } \\
\hline & Traumatic & Non-traumatic & Total & Traumatic & Non-traumatic & Total \\
\hline Male & 9 & $2 \mathrm{I}$ & 30 & 21 & 12 & 33 \\
\hline Female & 3 & 14 & 17 & 2 & 14 & I 6 \\
\hline Total & & & 47 & & & 49 \\
\hline
\end{tabular}

Table VIII relates contact lens wear to whether the right or left eye was aphakic. on In the non-traumatic group, patients with right aphakia maintained contact lens wear considerably better than those with left aphakia. This finding did not apply to the smaller $\vec{\sigma}$ traumatic group.

Table VIII Contact lens wear related to right or left aphakia in 96 patients

\begin{tabular}{|c|c|c|c|c|c|c|}
\hline \multirow{3}{*}{$\begin{array}{l}\text { Aphakic } \\
\text { eye }\end{array}$} & \multicolumn{6}{|l|}{ Contact lens } \\
\hline & \multicolumn{3}{|l|}{ Worn } & \multicolumn{3}{|l|}{ Not worn } \\
\hline & Traumatic & Non-traumatic & Total & Traumatic & Non-traumatic & Total \\
\hline Right & 5 & 21 & 26 & 13 & I I & 24 \\
\hline Left & 7 & 14 & 2 I & 10 & I 5 & 25 \\
\hline Total & & & 47 & & & 49 \\
\hline
\end{tabular}

Table IX relates contact lens wear to the visual acuity obtained in the aphakic eye with the contact lens. It is evident that the higher the visual acuity, the greater the proportion of patients maintaining contact lens wear, whether the aetiology of the cataract was traumatic or non-traumatic.

Table IX Contact lens wear related to visual acuity of aphakic eye in 96 patients

\begin{tabular}{|c|c|c|c|c|c|c|}
\hline \multirow{3}{*}{$\begin{array}{l}\text { Visual acuity } \\
\text { of aphakic eye } \\
\text { with contact } \\
\text { lens }\end{array}$} & \multicolumn{6}{|l|}{ Contact lens } \\
\hline & \multicolumn{3}{|l|}{ Worn } & \multicolumn{3}{|l|}{ Not worn } \\
\hline & Traumatic & Non-traumatic & Total & Traumatic & Non-traumatic & Total \\
\hline $6 / 4-6 / 5$ & 4 & I I & 15 & 3 & 4 & 7 \\
\hline $6 / 6-6 / 9$ & 8 & $2 \mathrm{I}$ & 29 & I3 & I9 & $3^{2}$ \\
\hline $6 / 12$ or less & o & 3 & 3 & 7 & 3 & 10 \\
\hline Total & & & 47 & & & 49 \\
\hline
\end{tabular}


Table $\mathrm{X}$ relates contact lens wear to the relative visual acuities of the aphakic eye with the contact lens and the phakic eye. As might be expected, the figures are very similar to those in Table IX.

Table $\mathbf{X}$ Contact lens wear related to visual acuity in each eye in 95 patients

\begin{tabular}{|c|c|c|c|c|c|c|}
\hline \multirow{3}{*}{$\begin{array}{l}\text { Visual acuity } \\
\text { of aphakic eye } \\
\text { compared with } \\
\text { phakic eye }\end{array}$} & \multicolumn{6}{|l|}{ Contact lens } \\
\hline & \multicolumn{3}{|l|}{ Worn } & \multicolumn{3}{|l|}{ Not worn } \\
\hline & Traumatic* & Non-traumatic & Total & Traumatic & Non-traumatic & Total \\
\hline $\begin{array}{l}2 \text { or more lines } \\
\text { Snellen better }\end{array}$ & 2 & I I & 13 & 0 & 5 & 5 \\
\hline $\begin{array}{l}\text { Within } 2 \text { lines } \\
\text { Snellen }\end{array}$ & 8 & $2 \mathrm{I}$ & 29 & 12 & 16 & 28 \\
\hline $\begin{array}{l}2 \text { or more lines } \\
\text { Snellen worse }\end{array}$ & $\mathbf{I}$ & 3 & 4 & II & 5 & I 6 \\
\hline Total & & & 46 & & & 49 \\
\hline
\end{tabular}

* I case omitted because of incomplete data

Table XI relates contact lens wear to the visual acuity in the phakic eye at the time of contact lens supply, which in the great majority of cases was the same as the visual acuity in that eye at the time of the contralateral cataract extraction. The relatively poor lens wear in patients with a high phakic visual acuity appears partly related to the preponderance of such patients in the traumatic group.

Table XI Contact lens wear related to visual acuity of phakic eye in 95 patients

\begin{tabular}{|c|c|c|c|c|c|c|}
\hline \multirow{3}{*}{$\begin{array}{l}\text { Visual } \\
\text { acuity of } \\
\text { phakic eye }\end{array}$} & \multicolumn{6}{|l|}{ Contact lens } \\
\hline & \multicolumn{3}{|l|}{ Worn } & \multicolumn{3}{|l|}{ Not worn } \\
\hline & Traumatic* & Non-traumatic & Total & Traumatic & Non-traumatic & Total \\
\hline $6 / 4-6 / 5$ & 2 & 5 & 7 & II & 8 & 19 \\
\hline $6 / 6-6 / 9$ & 9 & 24 & 33 & I I & 13 & 24 \\
\hline $6 / 12$ or less & o & 6 & 6 & I & 5 & 6 \\
\hline Total & & & 46 & & & 49 \\
\hline
\end{tabular}

$*_{1}$ case omitted because of incomplete data

Table XII (overleaf) relates contact lens wear to the interval between operation and the time of contact lens supply. In one patient with a dislocated lens due to non-penetrating trauma, the time interval was calculated from the date of injury. The figures fail to provide support for the concept that early contact lens fitting after cataract operation favours successful long-term wear, but this may be due to patient selection. However, in the traumatic group, the four patients who had a contact lens supplied within 6 months of the original injury all continued to wear the lenses.

Table XIII (overleaf) lists the primary reasons given for failure to maintain contact lens wear in (a) the 26 patients in the non-traumatic and (b) the 23 patients in the traumatic group. 
Table XII Contact lens wear related to fitting delay in 96 patients

\begin{tabular}{|c|c|c|c|c|c|c|}
\hline \multirow{3}{*}{$\begin{array}{l}\text { Interval from } \\
\text { operation to } \\
\text { contact lens supply }\end{array}$} & \multicolumn{3}{|l|}{ Contact lens } & & & \\
\hline & \multicolumn{3}{|l|}{ Worn } & \multicolumn{3}{|l|}{ Not worn } \\
\hline & Traumatic & Non-traumatic & Total & Traumatic & Non-traumatic & Total \\
\hline Less than $6 \mathrm{mths}$ & 8 & 23 & $3^{I}$ & 13 & 20 & 33 \\
\hline $6 \mathrm{mths}$ or more & 4 & 12 & 16 & 10 & 6 & 16 \\
\hline Total & 12 & 35 & 47 & 23 & 26 & 49 \\
\hline
\end{tabular}

Table XIII Reason for failure of contact lens wear in 49 patients

\begin{tabular}{|c|c|c|}
\hline \multirow{2}{*}{ Reason given for failure } & \multicolumn{2}{|l|}{ No. of patients } \\
\hline & Non-traumatic & Traumatic \\
\hline Irritation & 6 & I $\mathbf{I}$ \\
\hline Diplopia & 3 & 4 \\
\hline Binocular difficulties without diplopia & 3 & 3 \\
\hline Fogging of lens & 3 & - \\
\hline Occupation & $\mathbf{I}$ & 2 \\
\hline Difficulty in handling lens & 4 & - \\
\hline No subjective benefit & 2 & 2 \\
\hline Cosmetic & $\mathbf{I}$ & - \\
\hline Lens lost & 2 & $\mathbf{I}$ \\
\hline No reason given & I & - \\
\hline Total & 26 & 23 \\
\hline
\end{tabular}

(a) One patient with diplopia had a manifest divergent strabismus which was not $\stackrel{3}{3}$ completely eliminated before contact lens fitting in spite of two operations for its correction. One patient with binocular difficulties in the absence of diplopia had also had an operation for the correction of a manifest divergent strabismus before contact lens fitting. Excessive mucus secretion probably accounted for fogging of the lens in one patient, but the precise $\frac{0}{3}$ cause was unknown in the other two patients with this symptom. One patient, a marine fitter, discontinued wearing the contact lens because of the dust associated with that $\frac{}{3}$ occupation. Of the four patients with lens handling difficulties, one had arthritis ando two never mastered the basic techniques. The patient giving a cosmetic reason was $a_{D}$ female typist aged 32 years who did not like the look of the haptic lens, but it should be을. noted that a micro-corneal lens fitted initially was also unacceptable.

(b) Three of the four patients with diplopia had a manifest strabismus before contact $\tilde{D}^{\circ}$ lens fitting. Of these one had an operation for correction of the deviation before the $\omega$ contact lens fitting and two had similar operations after the fitting, one of the latter having two such operations. The two patients giving occupational reasons comprised $\stackrel{0}{\Phi}$ one who experienced irritation from fumes on starting new employment at a chemical $\stackrel{\oplus}{\rightarrow}$ factory and one who found working in a ship's boiler room caused irritation. 


\section{Discussion}

The results of this investigation confirm the findings of previous authors (Ruben, I962; Bonnet and others, I966) that long-term wear of a scleral contact lens is not achieved in a high proportion of patients with unilateral aphakia. In the present study, of the I 34 patients who were alive and could be traced, 46 per cent. were no longer wearing their contact lens, though nine of them had worn one successfully before cataract extraction in the second eye.

Contact lens wear was better maintained if the aetiology of the cataract was nontraumatic and if a good visual result was obtained in the aphakic eye, particularly if the acuity in that eye was better than in the phakic eye (see Maurer, I962). In the nontraumatic group, patients aphakic in the right eye wore their lenses considerably better than those in the left eye, possibly because of the factor of eye dominance (Welsh, ig6r). Patients over the age of 50 years tended to do better than younger patients, and in the nontraumatic group men maintained their contact lens wear better than women. Delay in fitting the contact lens after cataract surgery appeared to have no detrimental effect in the group studied. The four patients in the traumatic group who were supplied with a contact lens within 6 months of the injury all maintained contact lens wear in spite of the poor overall results in that group, but the feasibility of such early fitting was probably indicative of less severe trauma (see Foley, 1954).

Possibly because of patient selection, diplopia and other binocular difficulties comprised only a small proportion of the reasons for discontinuing contact lens wear. A manifest preoperative deviation, however, especially if severe enough to warrant strabismus surgery, carried a poor prognosis.

In spite of these findings, it would not appear possible to predict preoperatively in the individual patient undergoing cataract surgery that postoperative contact lens wear will not be maintained. It should also be noted that the aphakic visual acuity and therefore the relative acuities of the aphakic and phakic eye cannot be predicted at that stage, though they appear relevant to the success of subsequent contact lens wear.

Schirmer (1963a) reported that patients with a low corneal sensitivity to both pressure and friction, as tested with a specially designed Aesthesiometer (Schirmer, 1963b) using a large contact surface, tolerated contact lenses significantly better than patients with a high corneal sensitivity. Unfortunately, this technique would not seem applicable to patients about to undergo cataract section with the consequent division of corneal nerves and reduction in corneal sensitivity.

Because of the potential complications of an intraocular acrylic lens implant (Troutman, 1962; Choyce, 1964; Bresnick, 1969), we are firmly of the opinion that the insertion of an intraocular lens as a primary procedure is not warranted in patients who, at the time of preoperative assessment, seem suitable for contact lens fitting. However, if contact lens fitting appears to be inappropriate, for example on account of potential difficulty in handling the lens, the insertion of an intraocular lens at the time of cataract surgery (Binkhorst and Leonard, 1967) probably merits wider consideration than it has hitherto been accorded.

Though such a procedure may conveniently resolve the binocular problems created by unilateral cataract extraction, it can subsequently produce the very same predicament should cataract extraction become necessary on the second eye. The obvious course is to fit an intraocular lens in the second eye but technical difficulties may prevent this being achieved. The presence of less severe cataract in the second eye at the time of the 
initial cataract extraction may therefore be a further contraindication to primary intraocular lens implantation.

In spite of these considerations and the undoubted risks incurred when placing such implants in the eye, the long-term results of contact lens wear in unilateral aphakia offer no cause for complacency, and substantial improvement should be obtained by using a proportion of intraocular lens implants if the results of Binkhorst and Leonard (1967) can be reproduced.

The opportunities for primary implantation of such intraocular lenses in the treatment of traumatically-induced cataract must be few and almost invariably associated with greater risks than in the non-traumatic group. For these reasons there is rarely any necessity to consider such a procedure and secondary implantation can always be undertaken in suitable cases should a trial of contact lens wear prove unsuccessful.

\section{Summary}

A retrospective study of ${ }_{15}{ }^{6}$ patients fitted with scleral contact lenses for the optical ir correction of unilateral aphakia between $196 \mathrm{I}$ and $\mathrm{I} 966$ inclusive was made at the end ? of 1968 and the findings are analysed. It was not found possible to define factors by $\overrightarrow{\vec{\sigma}}$ which the failure to maintain such contact lens wear could be confidently predicted in 0 the individual patient before the cataract extraction. The possible indications for primary implantation of an intraocular acrylic lens are discussed in the light of these results.

Our thanks are due to Messrs. M. V. Graham and P. A. Graham for kindly allowing the inclusion of their patients in this study and to Prof. A. L. Cochrane, Director of the Medical Research Council, Epidemiological Research Unit (South Wales), whose staff assisted in tracing patients.

\section{References}

BINKHORST, c. D. (1959) Trans. ophthal. Soc. U.K., 79, 569

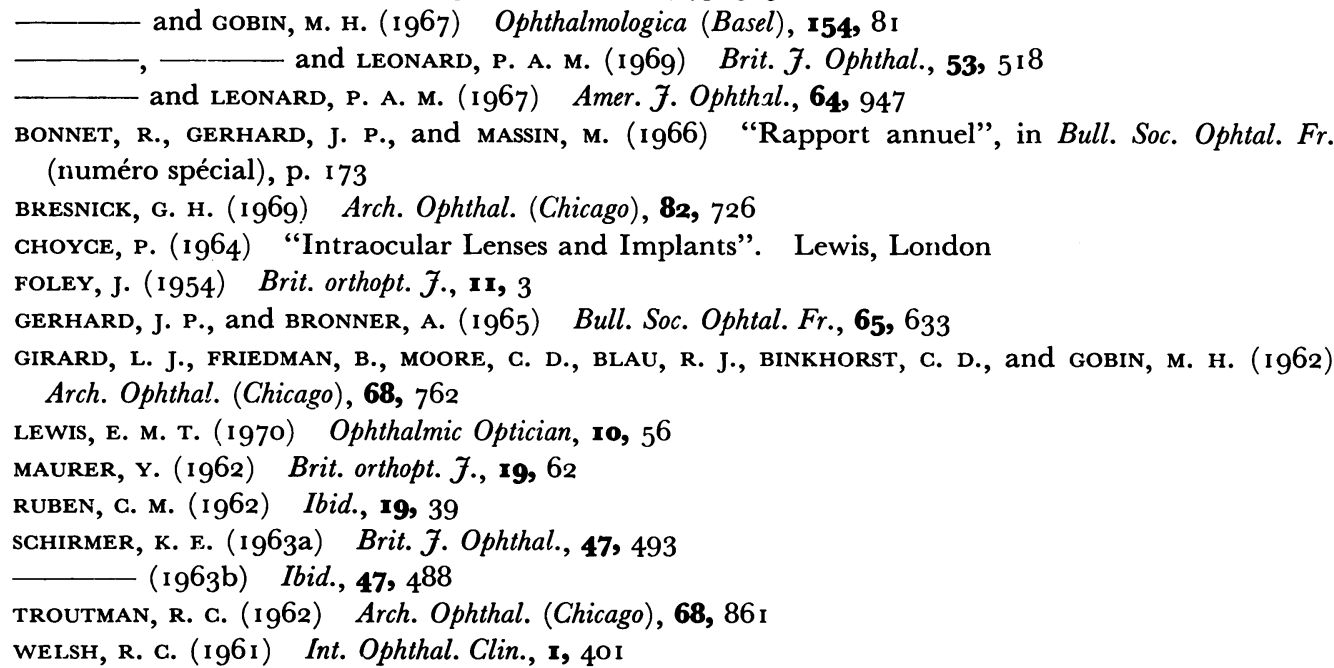

